Article

\title{
Soft Cationic Nanoparticles for Drug Delivery: Production and Cytotoxicity of Solid Lipid Nanoparticles (SLNs)
}

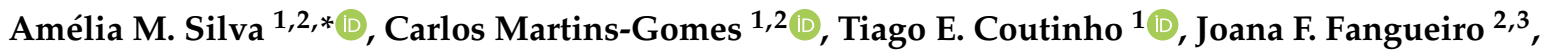 \\ Elena Sanchez-Lopez ${ }^{2,4}\left(\mathbb{D}\right.$, Tatiana N. Pashirova ${ }^{5}\left(\mathbb{D}\right.$, Tatiana Andreani ${ }^{2,6}$ and Eliana B. Souto ${ }^{3,7, * \mathbb{D}}$ \\ 1 Department of Biology and Environment, University of Trás-os Montes e Alto Douro (UTAD), \\ Quinta de Prados, 5001-801 Vila Real, Portugal; camgomes@utad.pt (C.M.-G.); tecoutinho@utad.pt (T.E.C.) \\ 2 Centre for Research and Technology of Agro-Environmental and Biological Sciences (CITAB-UTAD), \\ Quinta de Prados, 5001-801 Vila Real, Portugal; jffangueiro@gmail.com (J.F.F.); \\ esanchezlopez@ub.edu (E.S.-L.); tatiana.andreani@fc.up.pt (T.A.) \\ 3 Faculty of Pharmacy, University of Coimbra (FFUC), Pólo das Ciências da Saúde, Azinhaga de Santa Comba, \\ 3000-548 Coimbra, Portugal \\ 4 Department of Pharmacy and Pharmaceutical Technology and Physical Chemistry, Faculty of Pharmacy, \\ University of Barcelona, Ave. Joan XXIII s/n, 08028 Barcelona, Spain \\ 5 A.E. Arbuzov Institute of Organic and Physical Chemistry, Kazan Scientific Center, Russian Academy of \\ Sciences, Arbuzov str. 8, 420088 Kazan, Russia; tatyana_pashirova@mail.ru \\ 6 CIQUP-Research Center in Chemistry, Department of Chemistry and Biochemistry, Faculty of Sciences, \\ Porto University, Rua do Campo Alegre, s/n, 4169-007 Porto, Portugal \\ 7 CEB-Centre of Biological Engineering, University of Minho, Campus de Gualtar, 4710-057 Braga, Portugal \\ * Correspondence: amsilva@utad.pt (A.M.S.); ebsouto@ebsouto.pt (E.B.S.); \\ Tel.: +351-259350921 (A.M.S.); +351-239-488-400 (E.B.S.)
}

Received: 20 September 2019; Accepted: 16 October 2019; Published: 19 October 2019 updates

\begin{abstract}
The surface properties of nanoparticles have decisive influence on their interaction with biological barriers (i.e., living cells), being the concentration and type of surfactant factors to have into account. As a result of different molecular structure, charge, and degree of lipophilicity, different surfactants may interact differently with the cell membrane exhibiting different degrees of cytotoxicity. In this work, the cytotoxicity of two cationic solid lipid nanoparticles (SLNs), differing in the cationic lipids used as surfactants $\mathrm{CTAB}$ (cetyltrimethylammonium bromide) or DDAB (dimethyldioctadecylammonium bromide), referred as CTAB-SLNs and DDAB-SLNs, respectively, was assessed against five different human cell lines (Caco-2, HepG2, MCF-7, SV-80, and Y-79). Results showed that the cationic lipids used in SLN production highly influenced the cytotoxic profile of the particles, with CTAB-SLNs being highly cytotoxic even at low concentrations $\left(\mathrm{IC}_{50}<10 \mu \mathrm{g} / \mathrm{mL}\right.$, expressed as CTAB amount). DDAB-SLNs produced much lower cytotoxicity, even at longer exposure time (IC 50 from $284.06 \pm 17.01 \mu \mathrm{g} / \mathrm{mL}$ (SV-80) to $869.88 \pm 62.45 \mu \mathrm{g} / \mathrm{mL}$ (MCF-7), at $48 \mathrm{~h}$ ). To the best of our knowledge, this is the first report that compares the cytotoxic profile of CTAB-SLNs and DDAB-SLNs based on the concentration and time of exposure, using different cell lines. In conclusion, the choice of the right surfactant for biological applications influences the biocompatibility of the nanoparticles. Regardless the type of drug delivery system, not only the cytotoxicity of the drug-loaded nanoparticles should be assessed, but also the blank (non-loaded) nanoparticles as their surface properties play a decisive role both in vitro and in vivo.
\end{abstract}

Keywords: surfactants; cytotoxicity; SLNs; biocompatibility; CTAB; DDAB 


\section{Introduction}

Solid lipid nanoparticles (SLNs) were developed in the 1990s and were proposed as an alternative to traditional carriers (e.g., polymeric nanoparticles, liposomes). Since then SLNs have been receiving the attention of researchers from both academia and industry for a set of applications [1,2]. Solid lipid nanoparticles (SLNs) are colloidal carriers composed of a lipid matrix that is solid at body and room temperature (i.e., of melting point above $40^{\circ} \mathrm{C}$ ), and stabilized by appropriate surfactants [2,3]. In the last years, efforts have been made to develop SLN formulations with distinctive properties, e.g., capacity to improve the solubility of poorly water-soluble drugs and consequently their bioavailability, to enhance their targeting potential and cellular uptake, as well as their biological compatibility. SLNs are regarded as carriers with reduced toxicity [2-4], and have become popular in several areas, aiming to physicochemically protect the loaded drugs and to minimize their side-effects. In this regard, the components of nanoparticles aiming to deliver pharmaceutically active substances by routes, such as intravenous, oral, nasal pulmonary, must be of high grade and biocompatible to physiological systems. Other features to consider are the physicochemical properties of nanoparticles that influence stability and shelf-life of formulations, which can be improved by selecting the appropriate lipids and surfactants in the right combinations [2,5-7]. Surfactants are used to disperse the solid-lipid matrix in water thereby reducing the surface tension and energy to control the shape and prevent the risk of nanoparticles' aggregation under shelf life $[6,8,9]$.

Surfactants are defined as molecules with amphiphilic/amphipathic properties, having separate hydrophobic or solvophobic groups and hydrophylic or solvophilic properties. This feature arises from the chemical structure that consists of both a typically long alkyl chain (non-polar or hydrophobic groups, being named as "tails") and a polar or hydrophilic group (named as "heads") [10,11]. Surfactants are characterized by the presence or absence of charged groups in the head portion, being classified as ionic and non-ionic, respectively $[9,10]$. Depending on the total charge in the head group, ionic surfactants are further classified as (i) cationic, if positively charged, (ii) anionic, if negatively charged, and (iii) amphoteric, if presenting both a positive and a negative charge [11-13]. The behavior of amphoteric surfactants is $\mathrm{pH}$-dependent, being able of depicting a net positive charge (cationic) at low $\mathrm{pH}$, a net negative charge (anionic) at high $\mathrm{pH}$, and null net charge (zwitterionic) at intermediate $\mathrm{pH}$ values [13]. Surfactants have been used for a wide range of industrial applications in different sectors, e.g., foods, cosmetics, pharmaceuticals, with emphasis in the production of micro and nanoparticles [14]. The positive surface charge provided by the use of cationic surfactants may improve the cell-particle interaction as SLNs are attracted by the negatively charged membrane phospholipid. If negatively charged, such interaction is prevented or restrained.

However, the interaction of cationic SLNs with the cells may be followed by some degree of toxicity. Indeed, it has been documented that non-ionic surfactants are less toxic, than ionic surfactants [3,15], while cationic surfactants have been reported to produce higher toxicity, as a result of their higher interaction with cell membranes $[3,14,16]$. Among cationic surfactants, CTAB (cetyltrimethylammonium bromide) and DDAB (dimethyldioctadecylammonium bromide) have been used in various industrial processes (e.g., as biocides and antiseptic agents [17]), and in the production of drug-loaded nanoparticles for various applications [4,18-23]. While CTAB has a single chain and a single positive charged head-group, DDAB on the other hand is a double chain cationic lipid showing higher lipophilicity [24]. Because of these structural differences, CTAB and DDAB exhibit distinct capacity to interact and to disturb the plasmatic membrane of cells. Thus, the comparison of their toxicity under the same conditions is crucial for the selection of the less cytotoxic when designing SLNs for different administration routes and cell targets.

The aim of this work is to compare the in vitro biocompatibility of two types of SLNs differing in their cationic lipid composition (i.e., surface-tailored either with CTAB or with DDAB). To this aim, five different human cell lines were used: Caco-2 (epithelial colorectal adenocarcinoma), HepG2 (liver hepatocellular carcinoma), SV-80 (lung fibroblast), MCF-7 (breast adenocarcinoma), and Y-79 
(human retinoblastoma), mimicking several administration routes, for which a set of concentrations have been selected.

\section{Materials and Methods}

\subsection{Materials}

CTAB (cetyltrimethylammonium bromide; MW 364.45 g/mol, CAS Number: 57-09-0) was purchased from Sigma-Aldrich (Sintra, Portugal). DDAB (dimethyldioctadecylammonium bromide; MW 630.95 g/mol; CAS Number: 3700-67-2) was obtained from Avanti Polar Lipids (Alabama, USA). Softisan ${ }^{\circledR} 100$ (S100) was a gift from Sasol Germany GmbH (Witten, Germany), Lipoid ${ }^{\circledR}$ S75, composed of $75 \%$ soybean phosphatidylcholine was acquired from Lipoid GmbH (Ludwigshafen, Germany), Lutrol ${ }^{\circledR}$ F68 or Poloxamer 188 (P188) was a gift from BASF (Ludwigshafen, Germany). Anhydrous glycerol was acquired from Acopharma (Barcelona, Spain). In all assays ultra-pure water was used and obtained from a MiliQ Plus system (Millipore, Germany).

Other reagents and salts, not mentioned, were of high purity and were acquired from Sigma-Aldrich (Sintra, Portugal).

\subsection{Cationic SLNs Production}

Cationic SLNs were produced as previously reported by us [4,24,25], using the multiple emulsion (w/o/w) technique. This method produces SLNs of spherical shape, as reported by Fangueiro et al. [4]. Briefly, the lipid phase was composed of (in wt \%): glycerol (37.5), Sofitsan S100 (4.5), Lipoid S75 (0.5), cationic lipid (0.5 CTAB or 0.5 DDAB). A volume $(1.25 \mathrm{~mL})$ of ultra-pure water was added to the lipid phase at the same temperature $\left(5^{\circ} \mathrm{C}\right.$ to $10^{\circ} \mathrm{C}$ above the melting point of lipid S100) and then homogenized $(60 \mathrm{~s}$, sonication probe diameter $=6 \mathrm{~mm}$ ) using an ultrasonic processor VCX500 (Sonics, Switzerland). A power output, using an amplitude of $40 \%$, was applied. The solution of poloxamer $(1.0 \mathrm{wt} \%)$ was added and the mixture was then homogenized for $90 \mathrm{~s}$. This pre-emulsion was then poured in the total volume of poloxamer-cooled solution under magnetic stirring for $15 \mathrm{~min}$ to allow the SLN formation (formulation total volume $=20 \mathrm{~mL}$ ). The obtained SLNs dispersions were used for subsequent studies.

\subsection{Physicochemical Characterization}

Dynamic light scattering (DLS, Zetasizer Nano ZS, Malvern Instruments, Malvern, UK) was used to determine the physical parameters: mean particle size (Z-Ave) and polydispersity index (PI). All samples, diluted with ultra-purified water to suitable concentration, were analyzed in triplicate. Zeta potential (ZP) was also determined in ultra-purified water with the conductivity adjusted to $50 \mu \mathrm{S} / \mathrm{cm}$ (using $\mathrm{NaCl}$ solution at $0.9 \%, \mathrm{w} / \mathrm{V}$ ) to avoid ionic effects. Laser diffraction (LD) was performed also for particle size analysis using a Mastersizer Hydro 2000 MU (Malvern Instruments, Malvern, UK).

\subsection{Cell Culture and Viability Assay}

Cell culture and maintenance: Caco-2 (human epithelial colorectal adenocarcinoma), HepG2 (human liver hepatocellular carcinoma), and SV-80 (human lung fibroblast) cells were maintained in DMEM (Dulbecco's Modified Eagle Medium), MCF-7 (human breast adenocarcinoma) in DMEM/F12 (Dulbecco's Modified Eagle Medium: Nutrient Mixture F-12), and Y-79 (human retina retinoblastoma) in RPMI-1640 (Roswell Park Memorial Institute (RPMI) 1640 medium), supplemented with $10 \%$ (v/v) fetal bovine serum (FBS), $2 \mathrm{mM}$ L-glutamine, and antibiotics $(100 \mathrm{U} / \mathrm{mL}$ penicillin and $100 \mu \mathrm{g} / \mathrm{mL}$ of streptomycin) in an atmosphere of $5 \% \mathrm{CO}_{2}$ in air, at $37^{\circ} \mathrm{C}$ with controlled humidity. Cell lines: Caco-2, SV-80, and Y-79 were acquired from Cell Lines Service (CLS, Eppelheim, Germany), HepG2 and MCF-7 were acquired from ATCC (ATCC, Rockville, MD, USA). All cell culture media and supplements were from Gibco (Alfagene, Lisbon, Portugal). 
Cell preparation prior to cytotoxicity assays: Confluent cells were subjected to trypsin treatment (except Y-79, which grows in suspension), as described [26]. Briefly, after trypsinization, cells were counted, diluted in culture media to achieve a density of $5 \times 10^{4}$ cells $/ \mathrm{mL}$ and then were plated in 96-well plates $(100 \mu \mathrm{L} /$ well). Cells were further cultured, for at least $24 \mathrm{~h}$, to allow cell adherence and reestablishment of growth. Y-79 cells were aspirated from growing flasks using a serological pipette, placed in 15-mL sterile centrifuge tube and then centrifuged (to eliminate the supernatant). The pellet containing the cells was re-suspended in fresh culture media; as these cells form clusters. The cell cluster disaggregation was performed by applying gentle aspirations with a Pasteur pipette. After re-suspension and disaggregation, cells were counted, diluted to a density of $1 \times 10^{5} \mathrm{cells} / \mathrm{mL}$, in culture media, and then were seeded in 96 -well plates pre-coated with poly-L-lysine $(100 \mu \mathrm{L} /$ well, i.e., $1 \times 10^{4}$ cells/well). Cells were left in culture for at least $24 \mathrm{~h}$ to allow cell adherence.

Cytotoxicity/viability assay: Two different LNs formulations: CTAB-SLNs and DDAB-SLNs were assayed for cytotoxicity, at four concentrations, calculated as surfactant (CTAB or DDAB) concentration in the formulation, in $\mu \mathrm{g} \mathrm{mL}^{-1}: 66.0,165.0,330.0$, and 660.0. Test solutions were prepared just prior to cell application, by dispersing the required volume of particles in FBS-free culture media to achieve the desired final concentration. Test solutions ( $100 \mu \mathrm{L} /$ well; in quadruplicates) were added to the cells, after removing the growing culture media, and cells were exposed for $24 \mathrm{~h}$ or $48 \mathrm{~h}$ to test solutions before the cell viability assessment using the Alamar Blue (Invitrogen; Alfagene, Lisbon, Portugal), as previously reported $[27,28]$. Briefly, $24 \mathrm{~h}$ or $48 \mathrm{~h}$ after cell exposure, the incubating test solutions were removed and replaced by Alamar Blue solution $(10 \%(\mathrm{v} / \mathrm{v})$ in FBS-free culture media; $100 \mu \mathrm{L} /$ well). The absorbances, at 570 and $620 \mathrm{~nm}$ (reduced and oxidative form or resazurin, respectively [22]) were read $\sim 5 \mathrm{~h}$ after the addition of Alamar Blue solution. Data were analyzed by calculating the percentage of Alamar blue reduction (using the equations and procedures as previously reported $[4,26,27]$ ) and results were expressed as percentage of control (untreated cells).

Determination of $\mathrm{IC}_{50}$ : The $\mathrm{IC}_{50}$ (half maximal inhibitory concentration or concentration that inhibits $50 \%$ of cell viability/proliferation) was calculated as reported by Silva et al. [25], from each individual dose-response experiment using Excel or GraphPad Prism tolls $(n=3$ independent experiments; each experiment in quadruplicate). Each individual data was plotted as $\%$ cell viability ( $y$-axis) vs. concentration ( $x$-axis), fitted to a non-linear regression (logarithmic fitting; $Y=a \ln (X) \pm c$ ), and the $\mathrm{IC}_{50}$ values were calculated from obtained equations, making $Y=50 \%$ and obtaining the corresponding $X$ value, which gives the concentration that produces $50 \%$ viability. For each individual data-set, the $R^{2}$ values were between 0.85 and 0.99 . The $\mathrm{IC}_{50^{\prime}}$ values are indicated as the mean $\pm \mathrm{S}$.D. of $\mathrm{IC}_{50^{\prime}}$ calculated from three independent experiments, performed for each cell line and for each exposure time ( 24 or $48 \mathrm{~h}$ ).

\subsection{Statistical Analysis}

Statistical significance of cell viability results was determined using two-way analysis of variance (ANOVA), followed by Tukey multiple comparison test using $95 \%$ of confidence, i.e., obtained $p$-value $<0.05$ was set as significant between groups. Also, multiple $t$-test, using the Bonferroni-Dunn method ( $95 \%$ confidence) was used when needed. Data were expressed as mean value \pm standard deviation (mean $\pm \mathrm{SD}$ ) of $\mathrm{n}$ experiments, as indicated.

\section{Results and Discussion}

\subsection{SLNs Production and Characteristics}

SLNs production was performed using the multiple emulsion (w/o/w) technique, as previously reported [4]. DLS analysis indicated that the particles size was under $150 \mathrm{~nm}$, with a relatively narrow distribution $(<0.25)$, as shown in Table 1 . These SLN present relatively high positive ZP values $(\sim+28 \mathrm{mV})$, which is achieved because of the use of cationic lipids, CTAB and DDAB as surfactants. The strategic use of CTAB and DDAB, aimed the improvement of the particles' stability as a result of 
repulsion between positive surface charges, which is responsible for a reduction in particle aggregation and posterior dynamic changes in particle size. The interaction between particles and cells is favored by the positive charges at particles surface, as cells present a negative surface charge, which is a point in favor to improve the delivery of encapsulated material [3]. But, on the other hand, the increased interaction of nanoparticles with cells also may alter the cell membrane stability, resulting in cytotoxicity. Indeed, a previous work demonstrated that $\mathrm{CTAB}$, in a dose-dependent fashion, was an important contributor to cell cytotoxicity [4]. Laser diffraction results also showed that the mean particle size of these SLN was within the nanometer range, from $118 \mathrm{~nm}$ to $120 \mathrm{~nm}$, as shown in Table 1 . These results, i.e., surface charge and mean particle size, may contribute to improve the adhesion of SLNs to the cell membrane and their internalization to release the drug inside cells. These interactions may also interfere with cell metabolism and lead to toxicity. CTAB and DDAB have been selected as cationic surfactants for the production of CTAB-SLNs and DDAB-SLNs, respectively, as they are commonly used in the production of cationic nanoparticles.

Table 1. Mean particle size (Z-Ave), polydispersity index (PI), and zeta potential (ZP) of solid lipid nanoparticles (SLNs), recorded by dynamic light scattering (DLS), and d50\% measured by laser diffraction (LD). Results are indicated as mean \pm S.D. $(n=3)$.

\begin{tabular}{ccccc}
\hline \multirow{2}{*}{ Formulation } & \multicolumn{3}{c}{ DLS } & LD \\
\cline { 2 - 5 } & Z-Ave (nm) & PI & ZP (mV) & d50 (nm) \\
\hline CTAB-SLNs & $135.1 \pm 0.22$ & $0.196 \pm 0.02$ & $+28.20 \pm 1.33$ & $118.3 \pm 0.04$ \\
DDAB-SLNs & $134.2 \pm 1.12$ & $0.179 \pm 0.07$ & $+28.20 \pm 2.29$ & $119.8 \pm 0.01$ \\
\hline
\end{tabular}

\subsection{Assessment of CTAB and DDAB-Decorated SLNs Cytotoxicity}

Different cell lines were exposed to different concentrations of CTAB-SLNs and DDAB-SLNs, as shown in Table 2. The $\mathrm{wt} \%$, as concentration unit, is commonly used as a parameter in nanoparticles production. As these two surfactants have different molecular weights, Table 2 also shows the concentration (in $\mu \mathrm{M}$ ) of surfactants in SLNs.

Table 2. CTAB (cetyltrimethylammonium bromide) and DDAB (dimethyldioctadecylammonium bromide) concentrations of each test solution (in $\mu \mathrm{g} / \mathrm{mL}$ and in $\mu \mathrm{M}$ ) used in this study. See methods for details ( $w \mathrm{t} \%$ of CTAB and DDABB $(\mathrm{g} / 100 \mathrm{~mL})$ in formulation was 0.5$)$.

\begin{tabular}{cccccc}
\hline CTAB $\left(^{*}\right)$ & $\mu \mathrm{g} / \mathrm{mL}$ & $\mathbf{6 6 . 0}$ & $\mathbf{1 6 5 . 0}$ & $\mathbf{3 3 0 . 0}$ & $\mathbf{6 6 0 . 0}$ \\
& $\mu \mathrm{M}$ & 181.1 & 452.7 & 905.5 & 1810.9 \\
DDAB $\left(^{*}\right)$ & $\mu \mathrm{g} / \mathrm{mL}$ & $\mathbf{6 6 . 0}$ & $\mathbf{1 6 5 . 0}$ & 330.0 & $\mathbf{6 6 0 . 0}$ \\
& $\mu \mathrm{M}$ & 104.6 & 261.5 & 523.0 & 1046.0 \\
\hline
\end{tabular}

$\left.{ }^{*}\right)$, not present in the same formulation.

Figure 1 shows the effect of exposure to CTAB-SLNs and DDAB-SLNs in the different cell lines. CTAB-SLNs produced a drastic decrease of cell viability to values close to zero in all cell lines (Figure 1), which is translated by the low $\mathrm{IC}_{50}$ (Table 3) calculated for 24 and $48 \mathrm{~h}$ of exposure. For all cell lines, $\mathrm{IC}_{50}$ was $<10 \mu \mathrm{g} / \mathrm{mL}$ in both exposure times. In a study using Y-79 cells, Fangueiro et al. [4] demonstrated that the concentration of CTAB compromises the cell viability at concentrations above $0.5 \%(\mathrm{wt} \%)$ [4]. However, $\mathrm{CTAB}$ concentration is critical for the mean particle size. Indeed, that the mean particle size decreases with the increase of CTAB concentration $(239.5 \pm 0.61 \mathrm{~nm}$ to $144.7 \pm 1.61 \mathrm{~nm}$, at 0.25 and $1.0 \%(\mathrm{wt} \%)$, respectively [4]). The increase of CTAB concentration also increased the ZP of SLNs, from $+24 \mathrm{mV}($ at $0.25 \%)$ to $+48 \mathrm{mV}$ (at 1.0\%) favoring the particles' stability and their interactions with the cells [4]. 
A

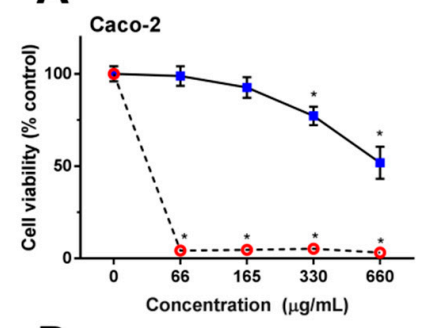

D

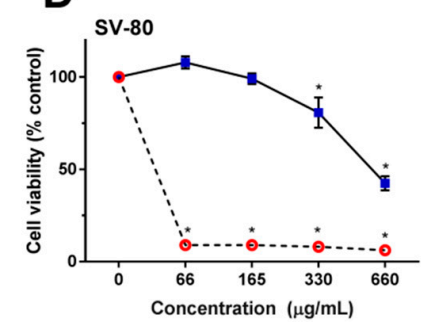

B

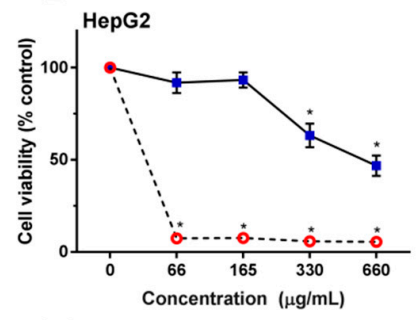

$E$

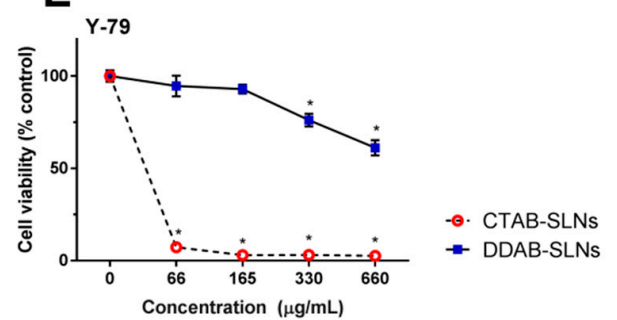

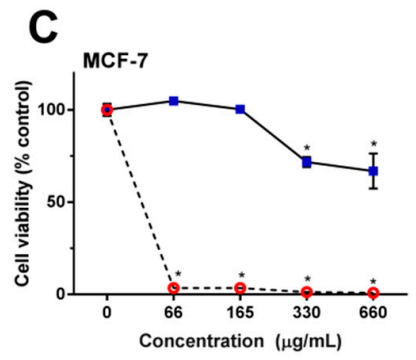

Figure 1. Cell viability profiles of CTAB-SLNs and DDAB-SLNs in Caco-2 (A), HepG2 (B), MCF-7 (C), SV-80 (D), and Y-79 (E) cells. Cells were exposed to CTAB-SLNs and DDAB-SLNs test solution, indicated in $\mu \mathrm{g} / \mathrm{mL}$ of surfactant in test solution $(66.0,165.0,330.0$, and 660.0), for $24 \mathrm{~h}$. Results, expressed as \% of control (non-exposed cells), indicate the mean $\pm \mathrm{SD}$ of $\mathrm{n}=3$ independent experiments (see methods). * Indicates statistical significance $(p<0.05)$ between control and different concentrations, for each condition (CTAB-SLNs and DDAB-SLNs). Statistical significance $(p<0.05)$ between the effect of DDAB-SLNs and CTAB-SLNs, at same concentration, was found to all values (not indicated).

Table 3. $\mathrm{IC}_{50}$ values calculated for each cell line exposed to CTAB-SLNs and DDAB-SLNs for 24 or $48 \mathrm{~h}$ (as indicated). Values represent the mean \pm S.D. (see methods for details).

\begin{tabular}{cccc}
\hline \multirow{2}{*}{ Cell Line } & \multirow{2}{*}{ Time } & \multicolumn{2}{c}{ IC50 $(\mu \mathrm{g} / \mathrm{mL}) *$} \\
\cline { 3 - 4 } & & CTAB-SLNs & DDAB-SLNs \\
\hline \multirow{2}{*}{ Caco-2 } & $24 \mathrm{~h}$ & $8.91 \pm 0.020$ & $983.99 \pm 97.01$ \\
& $48 \mathrm{~h}$ & $8.72 \pm 0.119$ & $845.20 \pm 54.98$ \\
\hline \multirow{2}{*}{ HepG2 } & $24 \mathrm{~h}$ & $9.70 \pm 0.158$ & $510.25 \pm 18.10$ \\
& $48 \mathrm{~h}$ & $9.04 \pm 0.026$ & $343.53 \pm 10.56$ \\
\hline \multirow{2}{*}{ MCF-7 } & $24 \mathrm{~h}$ & $8.91 \pm 0.099$ & $1121.14 \pm 104.28$ \\
& $48 \mathrm{~h}$ & $9.11 \pm 0.099$ & $869.88 \pm 62.45$ \\
\hline \multirow{2}{*}{ SV-80 } & $24 \mathrm{~h}$ & $9.31 \pm 0.079$ & $594.06 \pm 16.43$ \\
& $48 \mathrm{~h}$ & $8.91 \pm 0.152$ & $284.06 \pm 17.01$ \\
\hline \multirow{2}{*}{ Y-79 } & $24 \mathrm{~h}$ & $8.72 \pm 0.059$ & $1015.28 \pm 39.50$ \\
& $48 \mathrm{~h}$ & $9.24 \pm 0.059$ & $540.21 \pm 10.49$ \\
\hline
\end{tabular}

* Values given in $\mu \mathrm{g} / \mathrm{mL}$ of CTAB or DDAB in formulation.

The results from cytotoxicity and $\mathrm{IC}_{50}$ suggest that the choice of surfactant is relevant when designing formulations aiming the direct contact with the cells (i.e., intravenous injections or mucosal application), and thus caution has to be taken concerning the final concentration of CTAB.

Wang et al. produced gold nanoparticles (Au-NRs or nanorods) stabilized with CTAB [29]. The cytotoxic effect of both Au-NRs and CTAB was assessed against keratinocytes. The authors reported that the inherent toxicity of Au-NRs was mainly due to the presence of the cationic surfactant. CTAB decreased the cell viability at concentrations as low as $10 \mu \mathrm{M}$ (or $3.64 \mu \mathrm{g} / \mathrm{mL}$ ) [29], a value within the same range of concentrations here reported for CTAB-SLNs (Figure 1, Table 2). For some time, the toxicity of Au-NRs was attributed to the particle shape, but Qiu et al. [30] described that 
the toxicity was due to both the CTAB molecules surfacing Au-NRs and to those that were left in the suspended solution. CTAB molecules permeate cell membranes, enter the cell and damage the mitochondria resulting in depolarization, increased reactive oxygen species (ROS), and apoptosis. High and dose-dependent intracellular concentration of ROS was observed in HepG2 cells, either exposed to SLNs (containing CTAB as surfactant) or to CTAB alone, triggering oxidative stress and resulting in activation of intracellular antioxidant enzymes system [19].

The cytotoxicity of CTAB in human keratinocytes (HaCaT) and osteoblast-like (SAOS-2) cell lines, in the presence or absence of serum (FBS), was shown to be CTAB dose-dependent and was affected by the presence of FBS which clearly showed cell protection [15]. In the absence of FBS (the same conditions in which our incubations were performed), $200 \mu \mathrm{M}(72.88 \mu \mathrm{g} / \mathrm{mL})$ of surfactant reduced the metabolic activity of cells (SAOS-2 to $20 \%$ and $\mathrm{HaCaT}$ to less than $10 \%$ ), although in live/dead assays, at $200 \mu \mathrm{M}$ only a slight decrease in SAOS-2 cells viability was observed [15]. Although the metabolic activity is low, the percentage of dead cells is still low, suggesting that, after $24 \mathrm{~h}$ incubation, cells still trigger the apoptotic events.

On the other hand, DDAB-SLNs produced very low toxicity when compared to CTAB-SLNs (Figure 1 and Table 3), the cell viability being higher than $90 \%$ of control (for all tested cell lines), at $165 \mu \mathrm{g} / \mathrm{mL}$ DDAB (or, $261.51 \mu \mathrm{M}$; see Table 2), and higher than $50 \%$ for twice this concentration ( $330 \mu \mathrm{g} / \mathrm{mL}$; also for all cell lines). On average, cell viability was still above $50 \%$ for Caco-2 (Figure $1 \mathrm{~A})$, MCF-7 (Figure 1C), and Y-79 (Figure 1E) cells exposed to $660 \mu \mathrm{g} / \mathrm{mL}$ DDAB-SLNs. While all cell lines are highly and equally affected by CTAB-SLNs ( $\mathrm{IC}_{50}<10 \mu \mathrm{g} / \mathrm{mL}$; identical to all cell lines), the effect of DDAB-SLNs is cell line-dependent, and shows an order of potency (at $24 \mathrm{~h}$ exposure): HepG2 > SV-80 > Caco-2 > Y-79 > MCF-7, the IC $_{50}$ obtained for HepG2 and MCF-7 exposure to DDAB-NPs being $\sim 50$-fold and $\sim 130$-fold, respectively, higher than for CTAB-NPs exposure (Table 3 ). These results translate a higher safety profile of DDAB when compared to CTAB.

The effect of different sets of SLNs containing different concentrations of DDAB was tested in colorectal carcinoma (HCT-116) and bronchial epithelial (16-HBE) human cell lines [7], showing that at the highest tested SLN concentration $(500 \mu \mathrm{g} / \mathrm{mL}, \sim 40 \mu \mathrm{g} / \mathrm{mL}$ of DDAB), the loss of cell viability was $\sim 20 \%$ for both cell lines. These concentrations are significantly lower than those tested in our work (Figure 1), showing that toxicity might also be dependent on the other components of the formulation (Precirol ATO 5 and the surfactants Brij 76 [7]) and/or of the cell line. The $\mathrm{IC}_{50}$ values reported by Botto et al. [7], together with the observed low toxicity, is in line with our results. The effect of DDAB in solution was assessed in 29 human and non-human cell lines, showing a cell-dependent toxicity, the Neuro2a (mouse neuroblastoma; $\mathrm{EC}_{50}=0.64 \mu \mathrm{M} ; 0.40 \mu \mathrm{g} / \mathrm{mL}$ ) being the most affected with U-937 (Human leukemia; $\mathrm{EC}_{50}=2.12 \mu \mathrm{M} ; 1.33 \mu \mathrm{g} / \mathrm{mL}$ ) and, the MDCK (dog kidney; $\mathrm{EC}_{50}=21.4 \mu \mathrm{M}$; $13.50 \mu \mathrm{g} / \mathrm{mL}$ ) the least affected [31]. In this set of cells, A-172 (human glioblastoma; $\mathrm{EC}_{50}=15 \mu \mathrm{M}$; $9.46 \mu \mathrm{g} / \mathrm{mL}$ ), Caco-2, HepG2, and MCF-7 showed EC $_{50^{\prime}}$ s of $11.4 \pm 1.14,13.4 \pm 0.80$, and $9.63 \pm 4.11$, respectively [31], indicating that nanoparticles are less toxic than the individual counterparts. Kusumoto and Ishikawa [31] attributed cytotoxicity of DDAB to the formation of pores in cell membrane leading to apoptotic events, either intrinsic or extrinsic.

Other important and distinctive characteristic of these two surfactants is the critical micellar concentration (CMC; defined as the minimal concentration of surfactants that induces the spontaneous formation of micelles) [32,33], which is $\sim 1 \mathrm{mM}$ to CTAB [34] and $\sim 14 \mathrm{mM}$ to DDAB [35]. It has been reported that cell viability decrease and cell lysis only occur at or near the CMC of the surfactant [36], therefore the lowest tested $\mathrm{CTAB}$ and DDAB concentrations were $\sim 5$-fold and 134-fold lower than the respective $\mathrm{CMC}$. For this reason, we have observed a higher toxicity for $\mathrm{CTAB}$ as the used concentration is closer to the CMC.

In order to counteract the surfactant-induced toxicity, a preventive measure is to decrease the concentration of free/unbound surfactant in nanoparticles suspension by, e.g., centrifugation as described by Wang et al. [29]. However, this method does not prevent the CTAB-induced damage, as CTAB may eventually unbind from the nanoparticles $[29,37]$. Other strategies include the application 
of a coat to the surfactant layer, creating a barrier between the nanoparticle and the cell membrane, thereby preventing the toxic interaction. This coating can be made of several components, such as proteins (e.g., BSA), polyelectrolytes (e.g., polystyrene sulfonate), or silica [37].

With the results here discussed, one should always have in mind that the components of SLNs might be as toxic as the encapsulated drugs. Thus, if not previously assessed adequately, the non-specific damage caused by SLNs components might be higher than the desired therapeutic effect. Thus, not only the cytotoxicity of the drug-loaded SLNs should be assessed, but also the blank (non-loaded) SLNs as their surface properties play a decisive role both in vitro and in vivo.

\section{Conclusions}

SLNs require the use of surfactants to stabilize the size and charge in order to improve stability in suspension as well as cell internalization. However, some stabilizers may damage cells by direct interference with cell membrane integrity. In this work, CTAB was shown to be highly toxic compared to $\mathrm{DDAB}$ at the same concentration. All cell lines reduced their viability to values near zero in the presence of CTAB $\left(\mathrm{IC}_{50}<10 \mu \mathrm{g} / \mathrm{mL}\right)$, while DDAB-SLNs produced $\mathrm{IC}_{50}$ values that were about 50 -fold (HepG2) to 180-fold (MCF-7) higher than CTAB-SLNs, indicating the much lower toxicity of DDAB (Table 3). Thus, DDAB is tolerated by cells, while CTAB is highly toxic. One must bear in mind that these cells, used in in vitro assays, have no protection against membrane damaging agents. The same does not occur in vivo as other defense mechanisms may be active. Likewise, in dermal application the outer epidermal layer may protect the lower skin layers and the presence of connective tissue may act as a buffer to these agents, reducing the in vivo toxicity.

Author Contributions: A.M.S. and E.B.S. contributed for the conceptualization. A.M.S., C.M.-G., T.E.C., T.A., and J.F.F., methodology, data analysis, and investigation. A.M.S., C.M.-G., E.S.-L., and T.N.P. contributed for the writing-original draft preparation. All authors contributed to writing-review and editing. A.M.S. and E.B.S. contributed for supervision, project administration, resources, and funding acquisition.

Funding: This research was funded by the Portuguese Science and Technology Foundation, Ministry of Science and Education (FCT/MEC) through national funds, and co-financed by FEDER, under the project references M-ERA-NET/0004/2015 (PAIRED) and UID/AGR/04033/2019 (CITAB), co-financed by FEDER, under the Partnership Agreement PT2020.

Conflicts of Interest: The authors declare no conflict of interest.

\section{References}

1. Muller, R.H.; Shegokar, R.; Keck, C.M. 20 Years of Lipid Nanoparticles (SLN \& NLC): Present State of Development \& Industrial Applications. Curr. Drug Discov. Technol. 2011, 8, 207-227. [CrossRef] [PubMed]

2. Mishra, V.; Bansal, K.K.; Verma, A.; Yadav, N.; Thakur, S.; Sudhakar, K.; Rosenholm, J.M. Solid Lipid Nanoparticles: Emerging Colloidal Nano Drug Delivery Systems. Pharmaceutics 2018, 10, 191. [CrossRef] [PubMed]

3. Doktorovova, S.; Souto, E.B.; Silva, A.M. Nanotoxicology applied to solid lipid nanoparticles and nanostructured lipid carrier-A systematic review of in vitro data. Eur. J. Pharm. Biopharm. 2014, 87, 1-18. [CrossRef] [PubMed]

4. Fangueiro, J.F.; Andreani, T.; Egea, M.A.; Garcia, M.L.; Souto, S.B.; Silva, A.M.; Souto, E.B. Design of cationic lipid nanoparticles for ocular delivery: development, characterization and cytotoxicity. Int. J. Pharm. 2014, 461, 64-73. [CrossRef]

5. Matteucci, M.E.; Hotze, M.A.; Johnston, K.P.; Williams, R.O. Drug Nanoparticles by Antisolvent Precipitation: Mixing Energy versus Surfactant Stabilization. Langmuir 2006, 22, 8951-8959. [CrossRef]

6. Sui, Z.M.; Chen, X.; Wang, L.Y.; Xu, L.M.; Zhuang, W.C.; Chai, Y.C.; Yang, C.J. Capping effect of CTAB on positively charged Ag nanoparticles. Phys. E Low-Dimen. Syst. Nanostruct. 2006, 33, 308-314. [CrossRef]

7. Botto, C.; Mauro, N.; Amore, E.; Martorana, E.; Giammona, G.; Bondi, M.L. Surfactant effect on the physicochemical characteristics of cationic solid lipid nanoparticles. Int. J. Pharm. 2017, 516, 334-341. [CrossRef] 
8. Min, Y.; Akbulut, M.; Kristiansen, K.; Golan, Y.; Israelachvili, J. The role of interparticle and external forces in nanoparticle assembly. Nat. Mater. 2008, 7, 527. [CrossRef]

9. Elansezhian, R.; Ramamoorthy, B.; Nair, P.K. The influence of SDS and CTAB surfactants on the surface morphology and surface topography of electroless Ni-P deposits. J. Mater. Sci. Technol. 2009, 209, $233-240$. [CrossRef]

10. Oremusova, J.; Vitkova, Z.; Vitko, A.; Tarnik, M.; Miklovicova, E.; Ivankova, O.; Murgas, J.; Krchnak, D. Effect of Molecular Composition of Head Group and Temperature on Micellar Properties of Ionic Surfactants with C12 Alkyl Chain. Molecules 2019, 24, 651. [CrossRef]

11. Corazza, M.; Lauriola, M.M.; Zappaterra, M.; Bianchi, A.; Virgili, A. Surfactants, skin cleansing protagonists. J. Eur. Acad. Dermatol. Venereol.: JEADV 2010, 24, 1-6. [CrossRef] [PubMed]

12. Liu, Q.; Liu, S.; Luo, D.; Peng, B. Ultra-Low Interfacial Tension Foam System for Enhanced Oil Recovery. Appl. Sci. 2019, 9, 2155. [CrossRef]

13. Ivankovic, T.; Hrenovic, J. Surfactants in the environment. Arh. Za Hig. Rada I Toksikologiju 2010, 61, 95-110. [CrossRef] [PubMed]

14. Sharipova, A.A.; Aidarova, B.S.; Mutaliyeva, Z.B.; Babayev, A.A.; Issakhov, M.; Issayeva, B.A.; Madybekova, M.G.; Grigoriev, O.D.; Miller, R. The Use of Polymer and Surfactants for the Microencapsulation and Emulsion Stabilization. Colloids Interfaces 2017, 1, 3. [CrossRef]

15. Kalbacova, M.; Verdanova, M.; Mravec, F.; Halasova, T.; Pekar, M. Effect of CTAB and CTAB in the presence of hyaluronan on selected human cell types. Colloids Surf. A 2014, 460, 204-208. [CrossRef]

16. Effendy, I.; Maibach, H.I. Surfactants and experimental irritant contact dermatitis. Contact Dermat. 1995, 33, 217-225. [CrossRef]

17. Nabi, A.; Tasneem, S.; Jesudason, C.G.; Lee, V.S.; Zain, S.B.M. Study of interaction between cationic surfactant (CTAB) and paracetamol by electrical conductivity, tensiometric and spectroscopic methods. J. Mol. Liq. 2018, 256, 100-107. [CrossRef]

18. Gaidamauskas, E.; Cleaver, D.P.; Chatterjee, P.B.; Crans, D.C. Effect of Micellar and Reverse Micellar Interface on Solute Location: 2,6-Pyridinedicarboxylate in CTAB Micelles and CTAB and AOT Reverse Micelles. Langmuir 2010, 26, 13153-13161. [CrossRef]

19. Doktorovova, S.; Santos, D.L.; Costa, I.; Andreani, T.; Souto, E.B.; Silva, A.M. Cationic solid lipid nanoparticles interfere with the activity of antioxidant enzymes in hepatocellular carcinoma cells. Int. J. Pharm. 2014, 471, 18-27. [CrossRef]

20. Doktorovova, S.; Shegokar, R.; Rakovsky, E.; Gonzalez-Mira, E.; Lopes, C.M.; Silva, A.M.; Martins-Lopes, P.; Muller, R.H.; Souto, E.B. Cationic solid lipid nanoparticles (cSLN): Structure, stability and DNA binding capacity correlation studies. Int. J. Pharm. 2011, 420, 341-349. [CrossRef]

21. Doktorovova, S.; Shegokar, R.; Martins-Lopes, P.; Silva, A.M.; Lopes, C.M.; Müller, R.H.; Souto, E.B. Modified Rose Bengal assay for surface hydrophobicity evaluation of cationic solid lipid nanoparticles (cSLN). Eur. J. Pharm. Biopharm. 2012, 45, 606-612. [CrossRef] [PubMed]

22. Doktorovova, S.; Silva, A.M.; Gaivao, I.; Souto, E.B.; Teixeira, J.P.; Martins-Lopes, P. Comet assay reveals no genotoxicity risk of cationic solid lipid nanoparticles. J. Appl. Toxicol. 2014, 34, 395-403. [CrossRef] [PubMed]

23. Severino, P.; Szymanski, M.; Favaro, M.; Azzoni, A.R.; Chaud, M.V.; Santana, M.H.A.; Silva, A.M.; Souto, E.B. Development and characterization of a cationic lipid nanocarrier as non-viral vector for gene therapy. Eur. J. Pharm. Sci. 2015, 66, 78-82. [CrossRef] [PubMed]

24. Fangueiro, J.F.; Andreani, T.; Fernandes, L.; Garcia, M.L.; Egea, M.A.; Silva, A.M.; Souto, E.B. Physicochemical characterization of epigallocatechin gallate lipid nanoparticles (EGCG-LNs) for ocular instillation. Colloids Surf. B Biointerfaces 2014, 123, 452-460. [CrossRef]

25. Silva, A.M.; Martins-Gomes, C.; Fangueiro, J.F.; Andreani, T.; Souto, E.B. Comparison of antiproliferative effect of epigallocatechin gallate when loaded into cationic solid lipid nanoparticles against different cell lines. Pharm. Dev. Technol. 2019, 10, 1-7. [CrossRef]

26. Severino, P.; Andreani, T.; Jager, A.; Chaud, M.V.; Santana, M.H.; Silva, A.M.; Souto, E.B. Solid lipid nanoparticles for hydrophilic biotech drugs: Optimization and cell viability studies (Caco-2 \& HEPG-2 cell lines). Eur. J. Med. Chem. 2014, 81, 28-34. [CrossRef]

27. Andreani, T.; Kiill, C.P.; de Souza, A.L.R.; Fangueiro, J.F.; Fernandes, L.; Doktorovova, S.; Santos, D.L.; Garcia, M.L.; Gremiao, M.P.D.; Souto, E.B.; et al. Surface engineering of silica nanoparticles for oral insulin delivery: Characterization and cell toxicity studies. Colloids Surf. B Biointerfaces 2014, 123, 916-923. [CrossRef] 
28. Silva, A.M.; Alvarado, H.L.; Abrego, G.; Martins-Gomes, C.; Garduno-Ramirez, M.L.; Garcia, M.L.; Calpena, A.C.; Souto, E.B. In Vitro Cytotoxicity of Oleanolic/Ursolic Acids-Loaded in PLGA Nanoparticles in Different Cell Lines. Pharmaceutics 2019, 11, 362. [CrossRef]

29. Wang, S.; Lu, W.; Tovmachenko, O.; Rai, U.S.; Yu, H.; Ray, P.C. Challenge in understanding size and shape dependent toxicity of gold nanomaterials in human skin keratinocytes. Chem. Phys. Lett. 2008, 463, 145-149. [CrossRef]

30. Qiu, Y.; Liu, Y.; Wang, L.; Xu, L.; Bai, R.; Ji, Y.; Wu, X.; Zhao, Y.; Li, Y.; Chen, C. Surface chemistry and aspect ratio mediated cellular uptake of Au nanorods. Biomaterials 2010, 31, 7606-7619. [CrossRef]

31. Kusumoto, K.-I.; Ishikawa, T. Didodecyldimethylammonium bromide (DDAB) induces caspase-mediated apoptosis in human leukemia HL-60 cells. J. Control. Release 2010, 147, 246-252. [CrossRef]

32. Burilova, E.A.; Pashirova, T.N.; Lukashenko, S.S.; Sapunova, A.S.; Voloshina, A.D.; Zhiltsova, E.P.; Campos, J.R.; Souto, E.B.; Zakharova, L.Y. Synthesis, biological evaluation and structure-activity relationships of self-assembled and solubilization properties of amphiphilic quaternary ammonium derivatives of quinuclidine. J. Mol. Liq. 2018, 272, 722-730. [CrossRef]

33. Pashirova, T.; Burilova, E.; Lukashenko, S.; Gaysin, N.; Gnezdilov, O.; Sapunova, A.; Fernandes, A.; Voloshina, A.; Souto, E.B.; Zhiltsova, E.; et al. Nontoxic antimicrobial micellar systems based on mono and di-cationic Dabco-surfactants and furazolidone: Structure-solubilization properties relationships. J. Mol. Liq. 2019, in press.

34. Li, W.; Zhang, M.; Zhang, J.; Han, Y. Self-assembly of cetyl trimethylammonium bromide in ethanol-water mixtures. Front. Chem. China 2006, 1, 438-442. [CrossRef]

35. Mehta, S.K.; Bhawna; Bhasin, K.K.; Kumar, A. An insight into the micellization of dodecyldimethylethylammonium bromide (DDAB) in the presence of bovine serum albumin (BSA). J. Colloids Interface Sci. 2008, 323, 426-434. [CrossRef] [PubMed]

36. Partearroyo, M.A.; Ostolaza, H.; Goni, F.M.; Barbera-Guillem, E. Surfactant-induced cell toxicity and cell lysis: A study using B16 melanoma cells. Biochem. Pharmacol. 1990, 40, 1323-1328. [CrossRef]

37. Yasun, E.; Li, C.; Barut, I.; Janvier, D.; Qiu, L.; Cui, C.; Tan, W. BSA modification to reduce CTAB induced nonspecificity and cytotoxicity of aptamer-conjugated gold nanorods. Nanoscale 2015, 7, 10240-10248. [CrossRef] [PubMed] 